\title{
Common harms from amoxicillin: a systematic review and meta-analysis of randomized placebo-controlled trials for any indication
}

\author{
Malcolm Gillies PhD, Anggi Ranakusuma MD, Tammy Hoffmann PhD, Sarah Thorning MSc, \\ Treasure McGuire PhD, Paul Glasziou PhD, Christopher Del Mar MD
}

See related commentary, www.cmaj.ca/lookup/doi/10.1503/cmaj.141344. See related video, www.cmaj.ca/lookup/suppl/doi:10.1503 /cmaj.140848/-/DC1

\begin{abstract}
Background: When prescribing antibiotics for common indications, clinicians need information about both harms and benefits, information that is currently available only from observational studies. We quantified the common harms of the most frequently prescribed antibiotic, amoxicillin, from randomized placebo-controlled trials.
\end{abstract}

Methods: For this systematic review, we searched MEDLINE, Embase and the Cochrane Central Register of Controlled Trials, without language restriction, for any randomized, participant-blinded, placebo-controlled trials of amoxicillin or amoxicillin-clavulanic acid for any indication, in any setting. Our main outcome was any reported adverse event.

Results: Of 730 studies identified, we included 45 trials: 27 involving amoxicillin, 17 involving amoxicillin-clavulanic acid and 1 involving both. The indications for antibiotic therapy were variable. The risk of bias was low, although only 25 trials provided data suitable for assessment of harms, which suggested under-reporting. Diar- rhea was attributed to amoxicillin only in the form of amoxicillin-clavulanic acid (Peto odds ratio [OR] 3.30, 95\% confidence interval [CI] 2.23-4.87). The OR for candidiasis (3 trials) was significantly higher (OR 7.77, 95\% Cl 2.23-27.11). Rashes, nausea, itching, vomiting and abnormal results on liver function tests were not significantly increased. The results were not altered by sensitivity analyses, nor did funnel plots suggest publication bias. The number of courses of antibiotics needed to harm was $10(95 \% \mathrm{Cl} 6-17)$ for diarrhea with amoxicillin-clavulanic acid and 27 (95\% Cl 24-42) for candidiasis with amoxicillin (with or without clavulanic acid).

Interpretation: Diarrhea was caused by use of amoxicillin-clavulanic acid, and candidiasis was caused by both amoxicillin and amoxicillin-clavulanic acid. Harms were poorly reported in most trials, and their true incidence may have been higher than reported. Nevertheless, these rates of common harms associated with amoxicillin therapy may inform decisions by helping clinicians to balance harms against benefits.
Competing interests: Malcolm Gillies's employer, NPS

MedicineWise, is an independent nonprofit organization funded by the Australian Government's Department of Health to promote quality use of medicines. Tammy

Hoffmann and Christopher Del Mar report grants from the National Health and Medical Research Council of Australia during the conduct of this study. Christopher Del Mar also reports personal fees from BMJ Books and Elsevier for activities outside the scope of this work. No other competing interests were declared.

This article has been peer reviewed.

Correspondence to: Chris Del Mar, cdelmar @bond.edu.au

CMAJ 2015. DOI:10.1503 /cmaj.140848
$\mathrm{M}$ ost antibiotics are prescribed by primary care clinicians for common infections, particularly acute respiratory infections. ${ }^{1}$ However, for most acute respiratory infections, antibiotics provide only marginal benefits, and an inevitable consequence of this injudicious use is the prospect of antibiotic resistance. One way to reduce antibiotic prescribing in primary care is to explain to patients how little these drugs help for many common infections and to apply a process of shared decision-making during the consultation. ${ }^{2}$

The practice of shared decision-making requires not just an explanation of the paucity of benefits of antibiotics in most primary care situations, but also an explanation of the potential harms. Serious harms are probably sufficiently rare to be discounted by most clinicians and their patients. ${ }^{3}$ Yet when the decision to use or not use antibiotics relates to a self-remitting illness, for which the benefits are likely to be modest at best, the more common, mild harms of antibiotics become important. Unfortunately, common harms from antibiotics are poorly quantified, and clinicians cannot talk to patients with confidence about their likelihood.

Current understanding of the common harms of antibiotics is derived largely from observational studies. However, estimates of common harms from such studies may be biased, principally because it is difficult to distinguish adverse drug reactions from disease-related symptoms. 
One approach to addressing this problem is to investigate common harms encountered in randomized controlled trials of antibiotic against placebo. This study design controls for diseaserelated symptoms, allowing for better quantification of antibiotic-related adverse effects.

The most common antibiotic used in primary care is amoxicillin, either alone or in combination with clavulanic acid. "Common harms" can be defined as those frequent enough to be observable in the patient samples of most randomized trials and occurring during the recording of primary outcomes in such studies (with recognition that some of the adverse effects will occur later).

Accordingly, we systematically reviewed all published placebo-controlled randomized trials

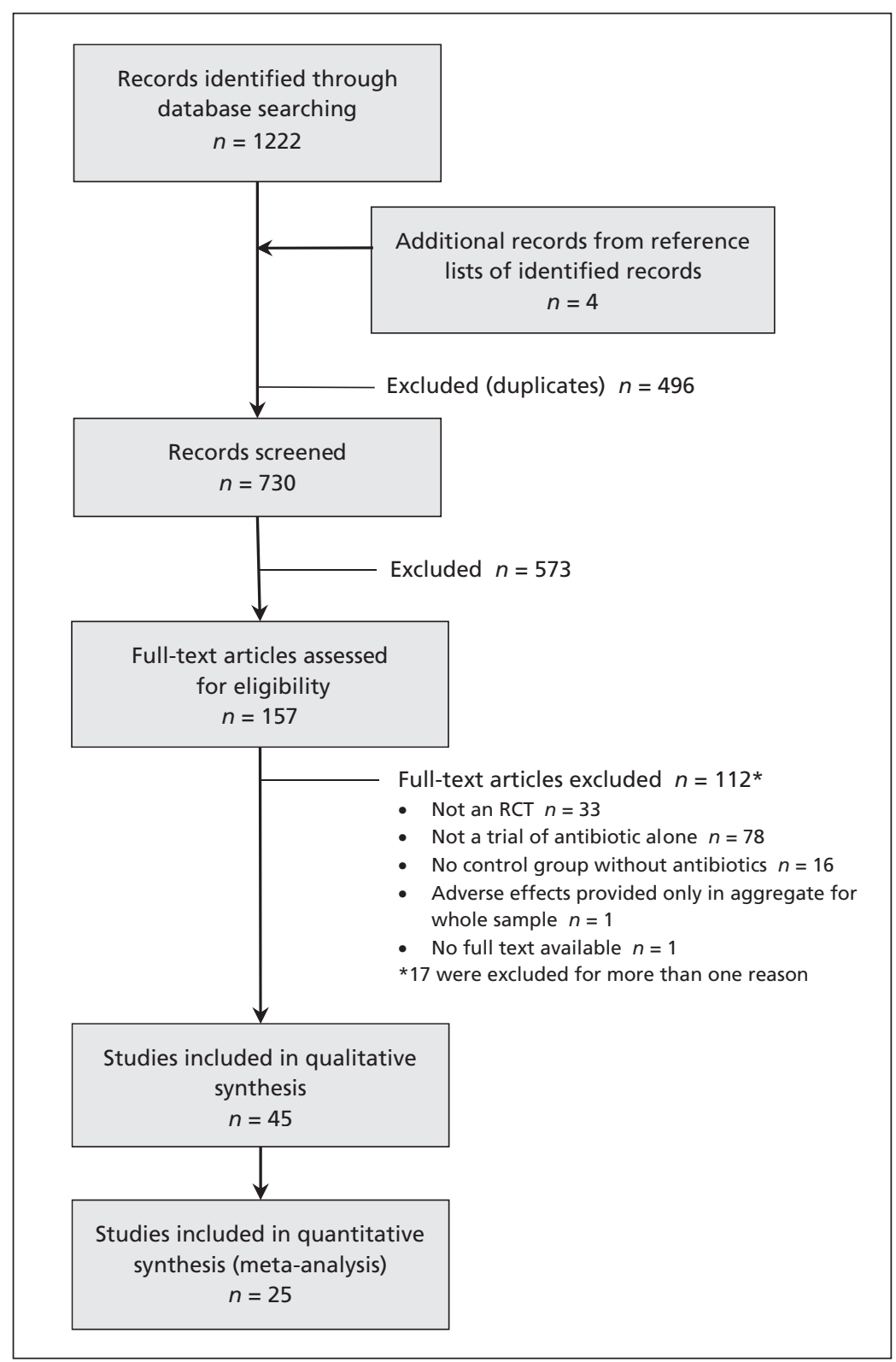

Figure 1: Selection of studies for inclusion in a meta-analysis of common harms in randomized placebo-controlled trials of amoxicillin or amoxicillin-clavulanic acid. of amoxicillin or amoxicillin-clavulanic acid for any indication, with the rationale that the risks of drug-induced harms are independent of the condition being treated. ${ }^{4}$

\section{Methods}

\section{Design and registration}

This systematic review with meta-analysis was registered with Prospero on May 11, 2012 (protocol available at www.crd.york.ac.uk/prospero/, registration number CRD42012002281).

\section{Data sources}

We searched MEDLINE (1946 to June week 4, 2013), Embase (2010 to July 2013) and the Cochrane Central Register of Controlled Trials (to 2013, issue 7) using the Cochrane highly sensitive search strategy for randomized trials (for the full search strategy, see Appendix 1, available at www.cmaj.ca/lookup/suppl/doi:10.1503 /cmaj.140848/-/DC1).

\section{Study selection}

We considered all randomized, participant-blinded, placebo-controlled trials, in any language, with any population, in which amoxicillin or amoxicillinclavulanic acid was used to treat any condition. We excluded studies that involved coadministration of any drug other than acetaminophen (paracetamol).

\section{Main outcome}

Outcomes of interest were any reported adverse event, including nausea, vomiting, diarrhea, rash, candidiasis, itch and abnormal results on liver function tests.

\section{Data extraction and synthesis}

Two authors (M.G. and A.R.) independently screened the titles and abstracts of retrieved studies to identify those that appeared to meet the inclusion criteria. The full texts of these articles were similarly independently assessed for eligibility. Any disagreements were resolved by discussion, and a third author (C.D.M.) arbitrated if necessary. The two reviewers used a standardized form to independently extract data from eligible studies, including event rates (with the intentionto-treat population as the denominator) and estimates of bias. Discrepancies were resolved by discussion, and the same third author arbitrated if necessary. We examined the texts of included trials for reported adverse events and checked registration information at trial registers for all included trials. The two reviewers independently undertook risk-of-bias assessment using Cochrane methods. ${ }^{5}$ Disagreements were resolved by discussion, and the same third author arbitrated if 
necessary. We undertook sensitivity analyses based on patient age (adult or child), drug doses and durations of therapy, and we analyzed funnel plots to determine potential publication bias.

\section{Statistical analyses}

We used Peto odds ratios (ORs) to analyze the data (because of their paucity ${ }^{5}$ ) and calculated $95 \%$ confidence intervals (CIs). We planned several subgroup analyses (see protocol at www.crd.york .ac.uk/prospero/). The numbers needed to harm $(\mathrm{NNH})$ were estimated as follows: the OR for each harm was multiplied by the risk of harm with placebo (after converting this value to its odds) to derive the odds of harm in the antibiotic group; these odds were converted back to risks, and the absolute risk difference was then calculated. ${ }^{6}$

\section{Results}

\section{Studies identified}

We identified 730 studies (after removal of duplicates), of which 573 were classified as ineligible on the basis of their titles or abstracts. Of the remaining 157 studies, 45 were included in the qualitative analysis and 25 in the quantitative analysis (Figure 1).

\section{Description of studies}

The trials were published from 1977 to 2013 (Figure 2). The setting and reason for use of an antibiotic varied (Table 1): primary care (15
[33\%]), dental care (9 [20\%]), secondary care (i.e., referral; 20 [44\%]), treatment (25 [56\%]) or prophylaxis (20 [44\%]). The median duration of antibiotic therapy was 7 days (range 1 dose to $1 \mathrm{yr}$ ). Across all included studies, there were 10519 participants: 4280 received only amoxicillin, 1005 received amoxicillin-clavulanic acid, and 5234 received placebo (Table 1). Among the 25 trials that reported usable harms data, the mean number of types of harms reported was 2.7 (range $0-10$ ). Most study reports gave minimal information about harm ascertainment. For 12 studies (27\%) we could determine whether patients had been asked about specific harms; in 8 studies (18\%) patients used a diary to record harms.

Funnel plots for the harms from diarrhea and rash were symmetric (Appendix 2, www.cmaj .ca/lookup/suppl/doi:10.1503/cmaj.140848/-/DC1).

\section{Quality of studies}

We found a low risk of bias in the reporting of antibiotic harms, although the principal focus of each trial was efficacy (Appendix 3, www.cmaj.ca /lookup/suppl/doi:10.1503/cmaj.140848/-/DC1). However, the reporting of such harms was poor: only $25(56 \%)$ of the 45 studies reported harms in sufficient detail to allow meta-analysis of their data. The rate of studies reporting harms did not improve over time (Figure 2). Even studies that reported usable harms data rarely gave detailed information about how they were collected, and

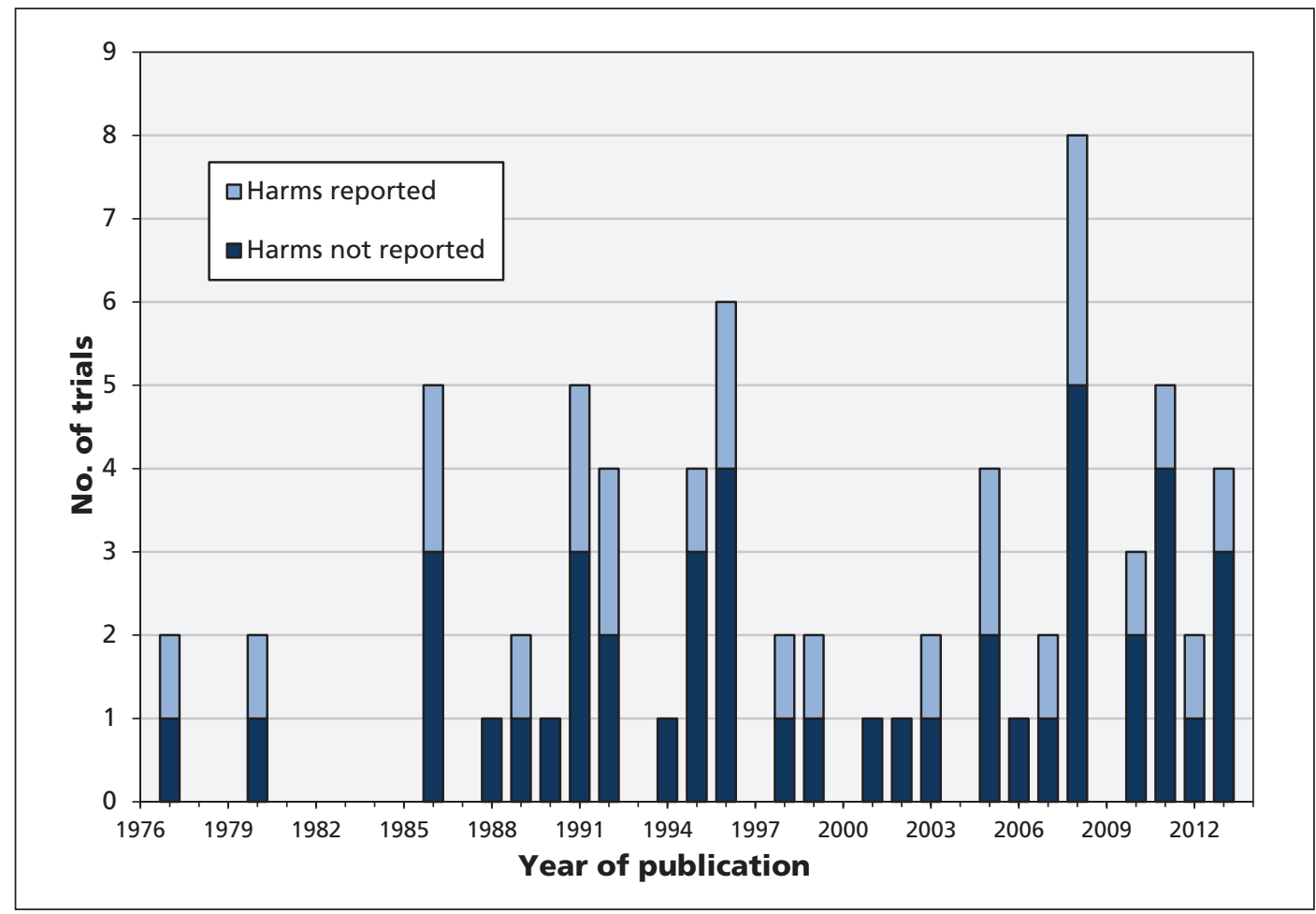

Figure 2: Number of trials, subdivided according to whether or not harms were reported, by year of publication. 


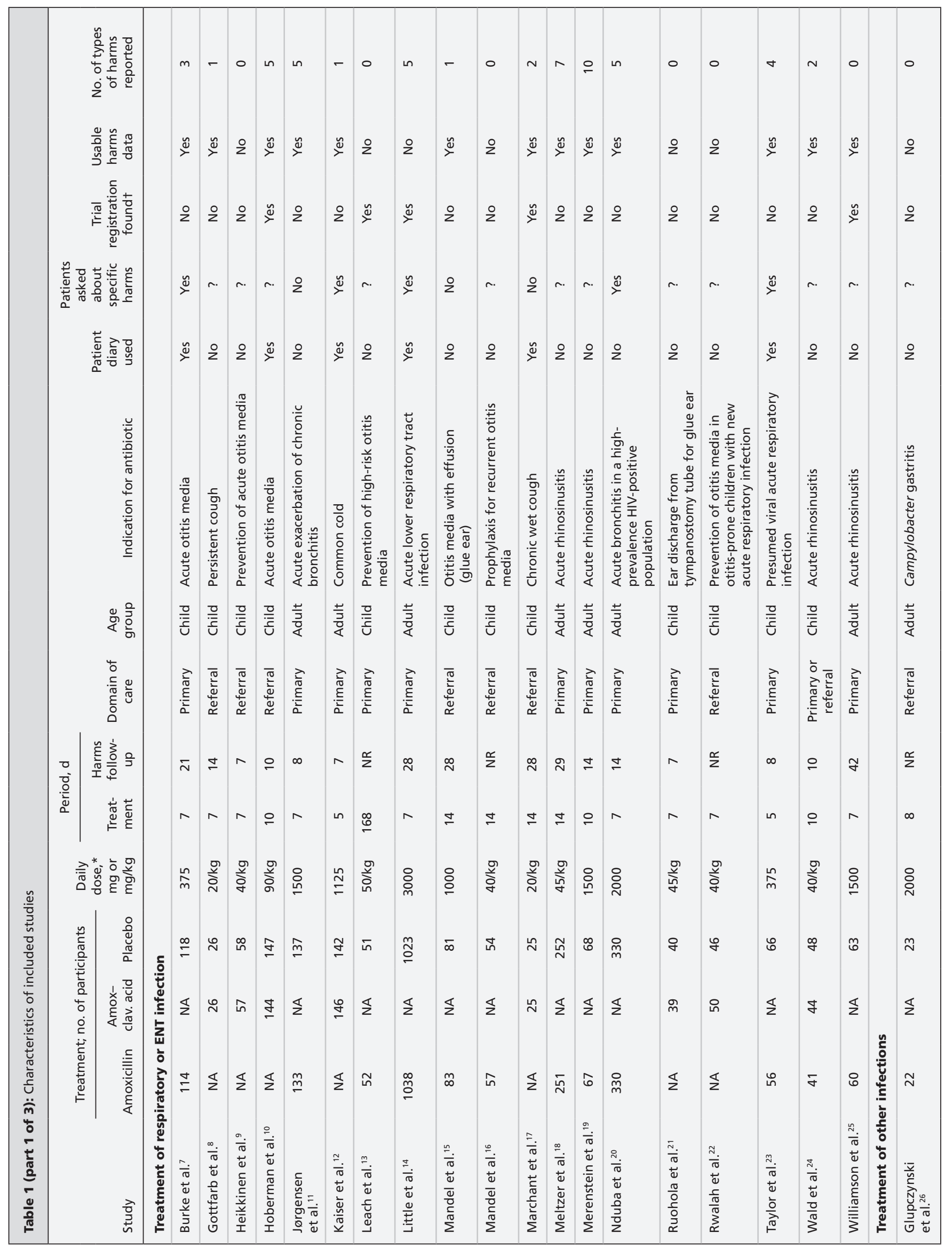




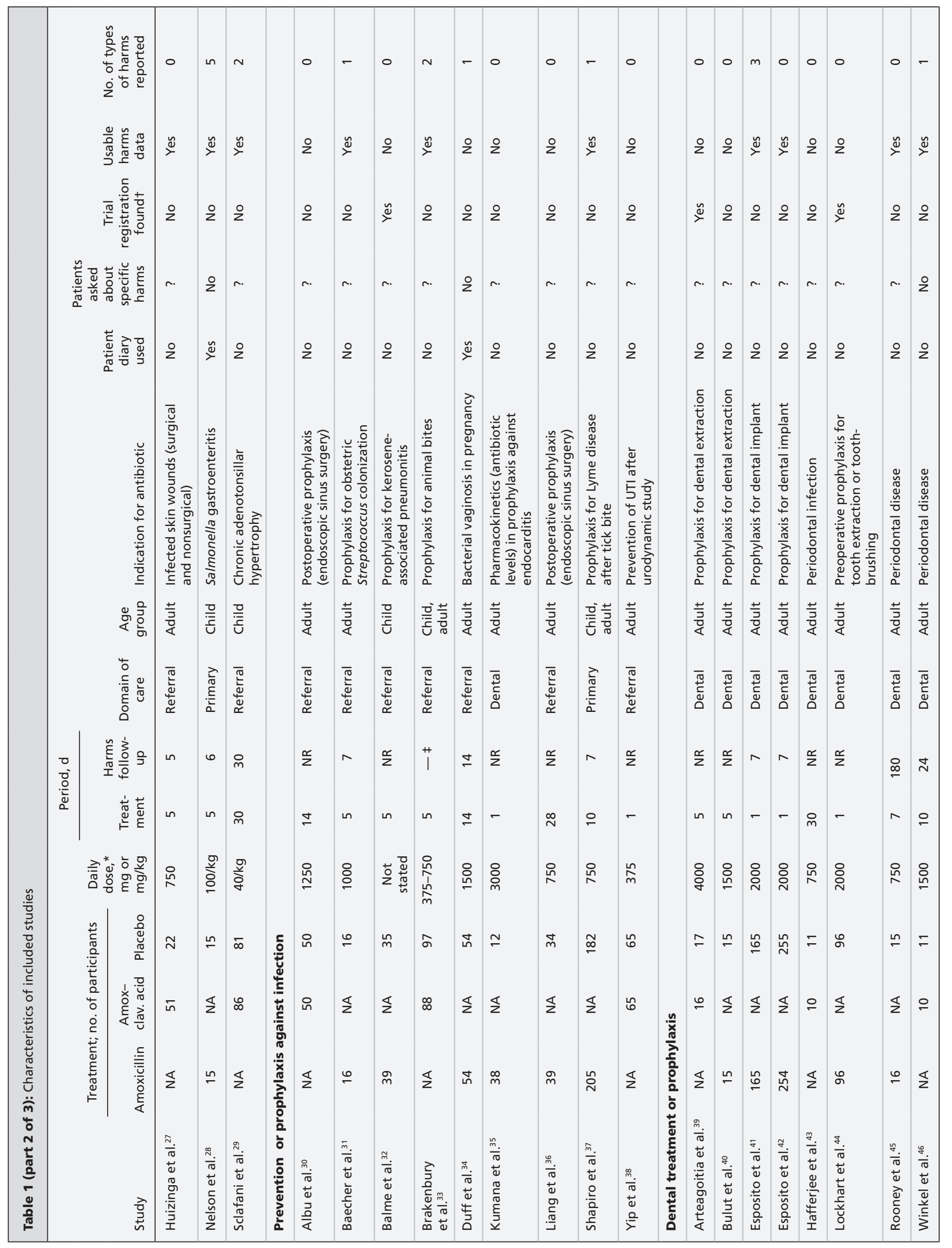




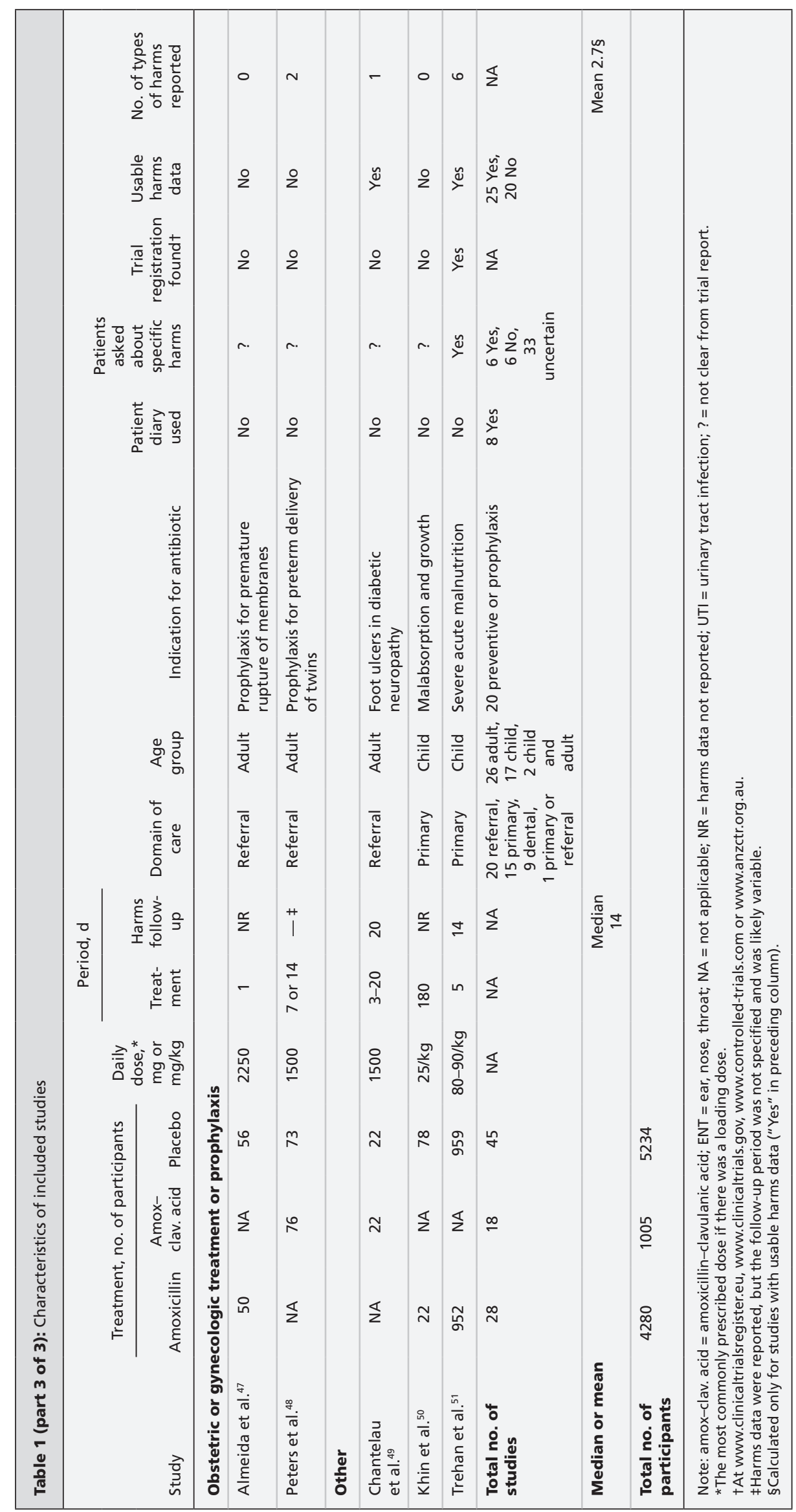


studies were sometimes unclear about whether all harms were reported (or, for example, whether they reported only those harms that led to withdrawal of patients from the trial). Nine trials were registered, but registering harms among the secondary outcomes did not guarantee that harms would be reported (Table 1), and registries did not provide any harms data that went unreported in the trials' primary publications.

\section{Meta-analysis of reported harms}

Diarrhea was reported in 17 studies and was not significantly caused by amoxicillin (overall OR $1.14,95 \%$ CI $0.98-1.33$ ), except in the combina-

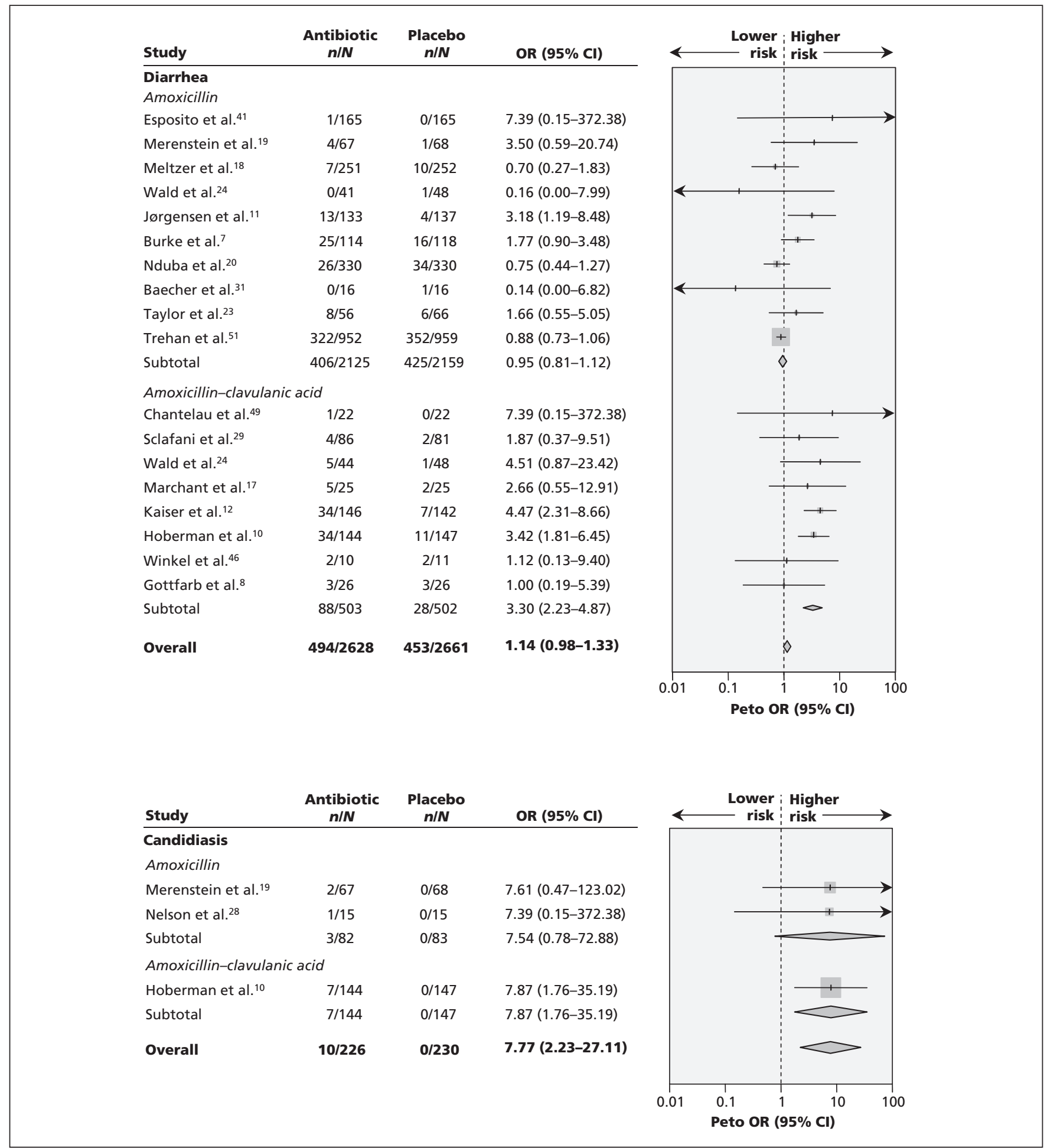

Figure 3A: Meta-analyses of reported harms with amoxicillin and amoxicillin-clavulanic acid: diarrhea and candidiasis. $\mathrm{Cl}=\mathrm{confidence}$ interval, $\mathrm{OR}=$ odds ratio. 


\begin{tabular}{lcccc} 
Study & $\begin{array}{c}\text { Antibiotic } \\
\boldsymbol{n} / \boldsymbol{N}\end{array}$ & $\begin{array}{c}\text { Placebo } \\
\boldsymbol{n} / \boldsymbol{N}\end{array}$ & OR (95\% Cl) \\
\hline Nausea & & & & \\
Amoxicillin & & & & \\
Meltzer et al. ${ }^{18}$ & $9 / 251$ & $7 / 252$ & $1.30(0.48-3.51)$ \\
Merenstein et al. ${ }^{19}$ & $4 / 67$ & $5 / 68$ & $0.80(0.21-3.09)$ \\
Nduba et al. ${ }^{20}$ & $92 / 330$ & $94 / 330$ & $0.97(0.69-1.36)$ \\
Subtotal & $105 / 648$ & $106 / 650$ & $0.99(0.72-1.35)$ \\
Overall & $\mathbf{1 0 5 / 6 4 8}$ & $\mathbf{1 0 6 / 6 5 0}$ & $\mathbf{0 . 9 9}(\mathbf{0 . 7 2 - 1 . 3 5 )}$
\end{tabular}

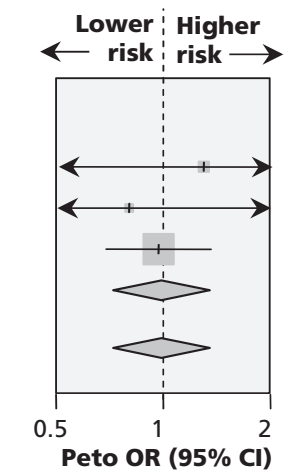

\begin{tabular}{|c|c|c|c|}
\hline Study & $\begin{array}{c}\text { Antibiotic } \\
n / N\end{array}$ & $\begin{array}{c}\text { Placebo } \\
n / N\end{array}$ & OR $(95 \% \mathrm{Cl})$ \\
\hline \multicolumn{4}{|l|}{ Vomiting } \\
\hline \multicolumn{4}{|l|}{ Amoxicillin } \\
\hline Merenstein et al. ${ }^{19}$ & $1 / 67$ & $0 / 68$ & $7.50(0.15-378.03)$ \\
\hline Nduba et al. 20 & $17 / 330$ & $18 / 330$ & $0.94(0.48-1.86)$ \\
\hline Burke et al. ${ }^{7}$ & 20/114 & $14 / 118$ & $1.57(0.76-3.25)$ \\
\hline Trehan et al..$^{51}$ & $114 / 952$ & $137 / 959$ & $0.82(0.63-1.06)$ \\
\hline Taylor et al. ${ }^{23}$ & $5 / 56$ & $7 / 66$ & $0.83(0.25-2.73)$ \\
\hline Subtotal & $157 / 1519$ & $176 / 1541$ & $0.89(0.71-1.12)$ \\
\hline \multicolumn{4}{|c|}{ Amoxicillin-clavulanic acid } \\
\hline Marchant et al. ${ }^{17}$ & $1 / 25$ & $0 / 25$ & $7.39(0.15-372.38)$ \\
\hline Hoberman et al. ${ }^{10}$ & $12 / 144$ & $11 / 147$ & $1.12(0.48-2.63)$ \\
\hline Subtotal & $13 / 169$ & $11 / 172$ & $1.22(0.53-2.81)$ \\
\hline Overall & $170 / 1688$ & $187 / 1713$ & $0.91(0.73-1.14)$ \\
\hline
\end{tabular}

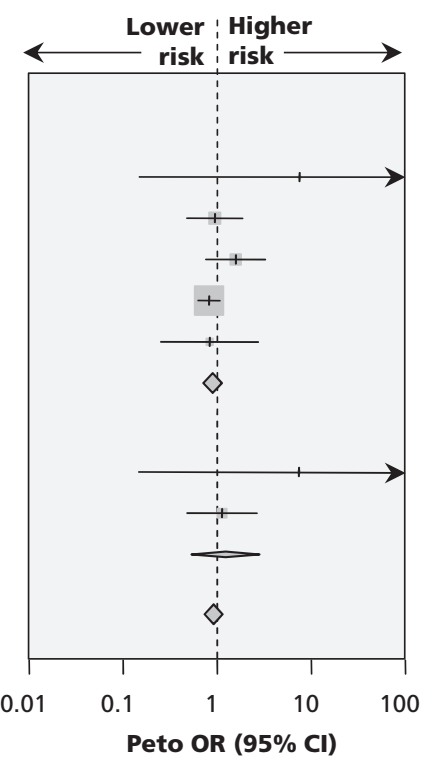

\begin{tabular}{|c|c|c|c|}
\hline Study & $\begin{array}{c}\text { Antibiotic } \\
n / N\end{array}$ & $\begin{array}{c}\text { Placebo } \\
n / N\end{array}$ & OR $(95 \% \mathrm{Cl})$ \\
\hline \multicolumn{4}{|l|}{ Rash } \\
\hline \multicolumn{4}{|l|}{ Amoxicillin } \\
\hline Merenstein et al. ${ }^{19}$ & $2 / 67$ & $0 / 68$ & $7.61(0.47-123.02)$ \\
\hline Shapiro et al. ${ }^{37}$ & $2 / 205$ & $0 / 182$ & $6.64(0.41-107.02)$ \\
\hline Jørgensen et al. ${ }^{11}$ & $3 / 133$ & $1 / 137$ & $2.83(0.39-20.34)$ \\
\hline Wald et al. ${ }^{24}$ & $1 / 41$ & $1 / 48$ & $1.17(0.07-19.23)$ \\
\hline Trehan et al..$^{51}$ & $43 / 952$ & $37 / 959$ & $1.18(0.75-1.84)$ \\
\hline Burke et al. ${ }^{7}$ & $10 / 114$ & $7 / 118$ & $1.52(0.57-4.06)$ \\
\hline Taylor et al. ${ }^{23}$ & $2 / 56$ & $6 / 66$ & $0.41(0.10-1.71)$ \\
\hline Subtotal & $63 / 1568$ & $52 / 1578$ & $1.25(0.86-1.82)$ \\
\hline \multicolumn{4}{|c|}{ Amoxicillin-clavulanic acid } \\
\hline Sclafani et al. ${ }^{29}$ & $2 / 86$ & $1 / 81$ & $1.85(0.19-18.04)$ \\
\hline Hoberman et al. ${ }^{10}$ & $1 / 144$ & $1 / 147$ & $1.02(0.06-16.40)$ \\
\hline Wald et al. ${ }^{24}$ & $0 / 44$ & $1 / 48$ & $0.15(0.00-7.44)$ \\
\hline Subtotal & $3 / 274$ & $3 / 276$ & $0.99(0.20-4.94)$ \\
\hline Overall & $66 / 1842$ & $55 / 1854$ & $1.24(0.86-1.78)$ \\
\hline
\end{tabular}

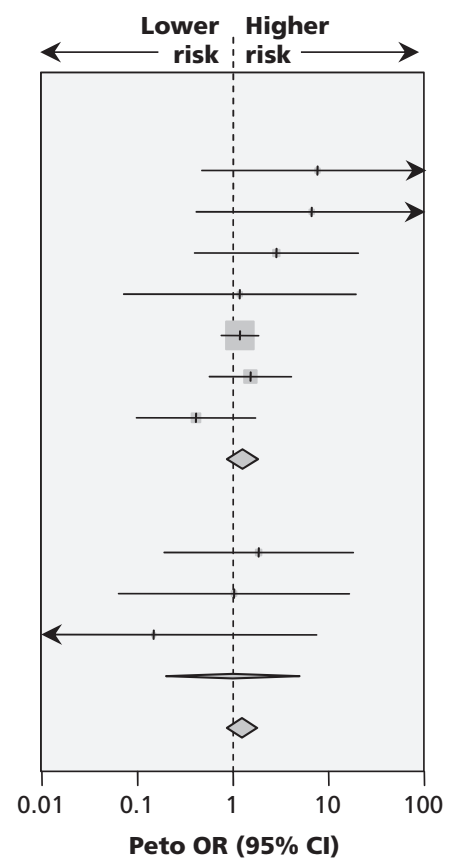

Figure 3B: Meta-analyses of reported harms with amoxicillin and amoxicillin-clavulanic acid: nausea, vomiting and rash. $\mathrm{Cl}=$ confidence interval, $\mathrm{OR}=$ odds ratio. 
tion form with clavulanic acid (OR 3.30 95\% 2.23-4.87) (test for subgroup differences $p<0.001$ ) (Figure 3A). There was high heterogeneity for all studies $\left(I^{2}=68.8 \%\right)$, but not for amoxicillin-clavulanic acid alone $\left(I^{2}=0 \%\right)$. The NNH for diarrhea was 10 (95\% CI 6-17).

Candidiasis, reported in only 3 studies, was significantly caused by amoxicillin (OR 7.77, 95\% CI 2.23-27.11,), with low heterogeneity (Figure 3A). The result was not significant for the subgroup of studies involving amoxicillin alone. The NNH for candidiasis was 27 (95\% CI 24-42). In addition to explicit candidiasis, one trial reported rates of diaper rash of about $50 \%$ among infants treated with amoxicillin-clavulanic acid. ${ }^{10}$ This rash was likely related to candidiasis as well. Analysis with inclusion of these data yielded the same OR value (data not shown).

Rashes, nausea and vomiting were not reported significantly more frequently with antibiotic than with placebo (Figure 3B). No trials reported itching, and only 1 trial reported abnormal results on liver function tests (which occurred in 2 placebotreated patients and 1 amoxicillin-treated patient). ${ }^{29}$

There were large variations in dose and duration of treatment among studies, and we explored this heterogeneity by subgroup analysis. Analyzing studies that used common doses of amoxicillin and those that used high doses, analyzing children and adults separately, and analyzing studies with common duration of therapy (roughly 1-2 wk) and those with long courses of therapy yielded the same summary effect sizes for diarrhea (see Appendix 4, www.cmaj.ca/lookup /suppl/doi:10.1503/cmaj.140848/-/DC1). There were too few studies reporting other outcomes to undertake subgroup analyses.

\section{Interpretation}

In this meta-analysis of randomized trials, we found statistically significant results for just 2 harms: diarrhea from amoxicillin-clavulanic acid and candidiasis from amoxicillin with or without clavulanic acid.

Reported harms were fewer than we expected from clinical anecdotal experience and observationally derived data, which have primarily reported common harms as rashes (at rates of $5 \%-8 \%$ of those treated and even higher, up to $20 \%$, among those with mononucleosis treated with amoxicillin) and gastrointestinal disturbance. Some standard textbooks do not report candidiasis. ${ }^{52,53}$ At least 1 casecontrol study found a relative risk of 7 for thrush after therapy with amoxicillin or amoxicillinclavulanic acid. ${ }^{54}$

Our reported rates of diarrhea (about $10 \%$ of courses of treatment) were similar to those in observational reports for amoxicillin-clavulanic $\operatorname{acid}^{53}$ and similar to the rates from observational studies of amoxicillin (2\%)..$^{52}$ Standard texts $^{52,53}$ report rash as common with these antibiotics, but we did not find a significant increase. However, the wide 95\% CI for the OR means that meta-analysis did not rule out rash as a common harm.

\section{Limitations}

The most important limitation of this systematic review derives from the fact that every trial had a primary outcome relating to efficacy rather than harm. Many of the studies failed to report any harms, which led us to suspect that their authors simply did not collect such information or, if they did, failed to publish it. This problem was compounded by the lack of published protocols and registry information for most trials, which prevented analysis of planned measures, thus creating potential for selective reporting. In some of the studies that did report them, harms were probably recorded passively (that is, recording these outcomes only if volunteered by patients, rather than routinely asking all patients about them), which means underestimation of their rates was likely. ${ }^{55}$ The low number of events also means that we had insufficient power to detect all but the most common harms. Each of these effects would lead to underestimation of harms.

One method of improving the power of a study like ours would be to undertake a network meta-analysis, including not only studies of antibiotic versus placebo, but also antibiotic versus other antibiotics (of which there are many), thereby exploiting differences among different antibiotics in their incidence of harms.

Nevertheless, these are currently the best estimates we can obtain for harms of these commonly prescribed antibiotics.

Well-conducted, relatively large trials of amoxicillin and amoxicillin-clavulanic acid continue to be conducted, and better estimates may therefore be possible in the future, particularly with respect to the relationship between harms and dose, length of treatment and population. However, the availability of usable harms data from future studies will depend on adequate reporting by trial authors. We found that usable harms data were lacking in many of the studies included in our analysis, despite the existence of a CONSORT extension statement designed to encourage better reporting of harms. ${ }^{56,57}$ In our sample of trials, there was no discernible improvement in the reporting of harms for trials published in the decade since this extension statement was published, compared with trials published before. 


\section{Conclusions}

Under-reporting of harms in trials remains widespread, ${ }^{58}$ and until that problem is addressed, under-reporting will flow to systematic reviews ${ }^{59}$ and other evidence syntheses such as guidelines. An important consequence of under-reporting of harms is misrepresentation of the balance of an intervention's benefits and harms, ${ }^{59}$ but shared decision-making requires consideration of both these aspects. This systematic review has provided new information about common harms of amoxicillin and amoxicillin-clavulanic acid that can contribute to better-informed discussions and decisions about the benefit-harm trade-off for these antibiotics. However, it also highlights that the ability of clinicians and patients to make fully informed decisions about using amoxicillin and amoxicillin-clavulanic acid is hampered by poor measurement and reporting.

\section{References}

1. Tan T, Little P, Stokes T; Guideline Development Group. Antibiotic prescribing for self limiting respiratory tract infections in primary care: summary of NICE guidance. BMJ 2008;337:a437.

2. Butler CC, Simpson SA, Dunstan F, et al. Effectiveness of multifaceted educational programme to reduce antibiotic dispensing in primary care: practice based randomised controlled trial. BMJ 2012;344:d8173.

3. Cosby JL, Francis N, Butler CC. The role of evidence in the decline of antibiotic use for common respiratory infections in primary care. Lancet Infect Dis 2007;7:749-56.

4. Cai Y, Wang R, Liang B, et al. Systematic review and metaanalysis of the effectiveness and safety of tigecycline for treatment of infectious disease. Antimicrob Agents Chemother 2011; 55:1162-72.

5. Higgins JPT, Green S, editors. Cochrane handbook for systematic reviews of interventions. Version 5.1.0. Oxford (UK): Cochrane Collaboration; 2011. Available: www.handbook.cochrane.org (accessed 2014 Sept. 25).

6. Cates CJ. Simpson's paradox and calculation of number needed to treat from meta-analysis. BMC Med Res Methodol 2002;2:1.

7. Burke P, Bain J, Robinson D, et al. Acute red ear in children: controlled trial of non-antibiotic treatment in general practice. BMJ 1991;303:558-62.

8. Gottfarb P, Brauner A. Children with persistent cough - Outcome with treatment and role of Moraxella catarrhalis? Scand J Infect Dis 1994;26:545-51.

9. Heikkinen T, Ruuskanen O, Ziegler T, et al. Short-term use of amoxicillin-clavulanate during upper respiratory tract infection for prevention of acute otitis media. J Pediatr 1995;126:313-6.

10. Hoberman A, Paradise JL, Rockette HE, et al. Treatment of acute otitis media in children under 2 years of age. $N$ Engl J Med 2011;364:105-15.

11. Jørgensen AF, Coolidge J, Pedersen PA, et al. Amoxicillin in treatment of acute uncomplicated exacerbations of chronic bronchitis. A double-blind, placebo-controlled multicentre study in general practice. Scand J Prim Health Care 1992;10:7-11.

12. Kaiser L, Lew D, Hirschel B, et al. Effects of antibiotic treatment in the subset of common-cold patients who have bacteria in nasopharyngeal secretions. Lancet 1996;347:1507-10.

13. Leach AJ, Morris PS, Mathews JD; Chronic Otitis Media Intervention Trial - One (COMIT1) group. Compared to placebo, long-term antibiotics resolve otitis media with effusion (OME) and prevent acute otitis media with perforation (AOMwiP) in a high-risk population: a randomized controlled trial. BMC Pediatr 2008:8:23.

14. Little P, Stuart B, Moore M, et al. Amoxicillin for acute lowerrespiratory-tract infection in primary care when pneumonia is not suspected: a 12-country, randomised, placebo-controlled trial. Lancet Infect Dis 2013;13:123-9.

15. Mandel EM, Rockette HE, Paradise JL, et al. Comparative efficacy of erythromycin-sulfisoxazole, cefaclor, amoxicillin or placebo for otitis media with effusion in children. Pediatr Infect Dis J 1991;10:899-906.
16. Mandel EM, Casselbrant ML, Rockette HE, et al. Efficacy of antimicrobial prophylaxis for recurrent middle ear effusion. Pediatr Infect Dis J 1996;15:1074-82.

17. Marchant J, Masters IB, Champion A, et al. Randomised controlled trial of amoxycillin clavulanate in children with chronic wet cough. Thorax 2012;67:689-93.

18. Meltzer EO, Bachert C, Staudinger H. Treating acute rhinosinusitis: comparing efficacy and safety of mometasone furoate nasal spray, amoxicillin, and placebo. J Allergy Clin Immunol 2005;116:1289-95.

19. Merenstein D, Whittaker C, Chadwell T, et al. Are antibiotics beneficial for patients with sinusitis complaints? A randomized double-blind clinical trial. J Fam Pract 2005;54:144-51.

20. Nduba VN, Mwachari CW, Magaret AS, et al. Placebo found equivalent to amoxicillin for treatment of acute bronchitis in Nairobi, Kenya: a triple blind, randomised, equivalence trial. Thorax 2008;63:999-1005.

21. Ruohola A, Heikkinen T, Meurman O, et al. Antibiotic treatment of acute otorrhea through tympanostomy tube: randomized double-blind placebo-controlled study with daily followup. Pediatrics 2003;111:1061-7.

22. Rwalah MM, Rashdan HAA. Short-course antibiotic to prevent acute otitis media in children with upper respiratory tract infection. Rawal Med J 2011;36:133-6.

23. Taylor B, Abbott GD, Kerr MM, et al. Amoxycillin and cotrimoxazole in presumed viral respiratory infections of childhood: placebo-controlled trial. BMJ 1977;2:552-4.

24. Wald ER, Chiponis D, Ledesma-Medina J. Comparative effectiveness of amoxicillin and amoxicillin-clavulanate potassium in acute paranasal sinus infections in children: a double-blind, placebo-controlled trial. Pediatrics 1986;77:795-800.

25. Williamson IG, Rumsby K, Benge S, et al. Antibiotics and topical nasal steroid for treatment of acute maxillary sinusitis: a randomized controlled trial. JAMA 2007;298:2487-96.

26. Glupczynski Y, Burette A, Labbe M, et al. Campylobacter pylori-associated gastritis: a double-blind placebo-controlled trial with amoxycillin. Am J Gastroenterol 1988;83:365-72.

27. Huizinga WK, Kritzinger NA, Bhamjee A. The value of adjuvant systemic antibiotic therapy in localised wound infections among hospital patients: a comparative study. J Infect 1986;13:11-6.

28. Nelson JD, Kusmiesz H, Jackson LH, et al. Treatment of Salmonella gastroenteritis with ampicillin, amoxicillin, or placebo. Pediatrics 1980;65:1125-30.

29. Sclafani AP, Ginsburg J, Shah MK, et al. Treatment of symptomatic chronic adenotonsillar hypertrophy with amoxicillin/ clavulanate potassium: short- and long-term results. Pediatrics 1998;101:675-81.

30. Albu S, Lucaciu R. Prophylactic antibiotics in endoscopic sinus surgery: a short follow-up study. Am J Rhinol Allergy 2010;24:306-9.

31. Baecher L, Grobman W. Prenatal antibiotic treatment does not decrease group B streptococcus colonization at delivery. Int $J$ Gynaecol Obstet 2008;101:125-8.

32. Balme KH, Zar HJ, Mann MD. A randomised controlled study on the efficacy of prophylactic antibiotics in the management of kerosene-associated pneumonitis at a tertiary children's hospital in South Africa [abstract]. Clin Toxicol 2013;51:335.

33. Brakenbury PH, Muwanga C. A comparative double blind study of amoxycillin/clavulanate vs placebo in the prevention of infection after animal bites. Arch Emerg Med 1989;6:251-6.

34. Duff P, Lee ML, Hillier SL, et al. Amoxicillin treatment of bacterial vaginosis during pregnancy. Obstet Gynecol 1991; 77:431-5.

35. Kumana CR, Chau KK, Chau PY, et al. Chemoprophylaxis with oral amoxycillin against bacterial endocarditis: When should second doses be administered after dentistry? Br Med J (Clin Res Ed) 1986;293:1532-4.

36. Liang KL, Su YC, Tsai CC, et al. Postoperative care with Chinese herbal medicine or amoxicillin after functional endoscopic sinus surgery: a randomized, double-blind, placebocontrolled study. Am J Rhinol Allergy 2011;25:170-5.

37. Shapiro ED, Gerber MA, Holabird NB, et al. A controlled trial of antimicrobial prophylaxis for Lyme disease after deer-tick bites. N Engl J Med 1992;327:1769-73.

38. Yip SK, Cheon C, Wong T, et al. Preventing female urinary tract infection caused by urodynamic study: a randomised doubleblind placebo-controlled trial of prophylactic Augmentin [abstract 047]. Int Urogynecol J Pelvic Floor Dysfunct 2006; 17:S85-6.

39. Arteagoitia M, Santamaria G, Ramos E, et al. Efficacy of amoxicillin/clavulanic acid 2000/125 mg in preventing infection after extraction of impacted mandibular third molar totally covered by bone: preliminary results. Int J Oral Maxillofac Surg 2011;40:1048-9. 
40. Bulut E, Bulut S, Etikan I, et al. The value of routine antibiotic prophylaxis in mandibular third molar surgery: acute-phase protein levels as indicators of infection. J Oral Sci 2001; 43:117-22.

41. Esposito M, Cannizzaro G, Bozzoli P, et al. Efficacy of prophylactic antibiotics for dental implants: a multicentre placebo-controlled randomised clinical trial. Eur J Oral Implantol 2008;1:23-31.

42. Esposito M, Cannizzaro G, Bozzoli P, et al. Effectiveness of prophylactic antibiotics at placement of dental implants: a pragmatic multicentre placebo-controlled randomised clinical trial. Eur J Oral Implantol 2010;3:135-43.

43. Haffajee AD, Dibart S, Kent RL Jr, et al. Clinical and microbiological changes associated with the use of 4 adjunctive systemically administered agents in the treatment of periodontal infections. J Clin Periodontol 1995;22:618-27.

44. Lockhart PB, Brennan MT, Sasser HC, et al. Bacteremia associated with toothbrushing and dental extraction. Circulation 2008; 117:3118-25.

45. Rooney J, Wade WG, Sprague SV, et al. Adjunctive effects to non-surgical periodontal therapy of systemic metronidazole and amoxycillin alone and combined. A placebo controlled study. J Clin Periodontol 2002;29:342-50.

46. Winkel EG, van Winkelhoff AJ, Barendregt DS, et al. Clinica and microbiological effects of initial periodontal therapy in conjunction with amoxicillin and clavulanic acid in patients with adult periodontitis. A randomised double-blind, placebocontrolled study. J Clin Periodontol 1999;26:461-8.

47. Almeida L, Schmauch A, Bergstrom S. A randomised study on the impact of peroral amoxicillin in women with prelabour rupture of membranes preterm. Gynecol Obstet Invest 1996;41:82-4

48. Peters MT, Brown CEL, Baum A, et al. Randomized, doubleblinded, placebo-controlled trial of amoxycillin/clavulanic acid to prevent preterm delivery in twin gestation. Infect Dis Obstet Gynecol 1995;3:158-63.

49. Chantelau E, Tanudjaja T, Altenhofer F, et al. Antibiotic treatment for uncomplicated neuropathic forefoot ulcers in diabetes: a controlled trial. Diabet Med 1996;13:156-9.

50. Khin-Maung-U, Bolin TD, Duncombe VM, et al. Effect of short-term intermittent antibiotic treatment on growth of Burmese (Myanmar) village children. Lancet 1990;336:1090-3.

51. Trehan I, Goldbach HS, LaGrone LN, et al. Antibiotics as part of the management of severe acute malnutrition. $N$ Engl J Med 2013;368:425-35

52. Geddes AM, Gould IM. Ampicillin, amoxicillin and other ampicillin-like penicillins. In: Grayson ML, Crowe SM, McCarthy JS, et al., editors. Kucers' the use of antibiotics. 6th ed. London (UK): Hodder Arnold; 2010. p. 65-92

53. Gordon D. Amoxicillin-clavulanic acid (co-amoxiclav). In Grayson ML, Crowe SM, McCarthy JS, et al., editors. Kucers the use of antibiotics. 6th ed. London (UK): Hodder Arnold; 2010. p. 187-203.

54. MacDonald TM, Beardon PH, McGilchrist MM, et al. The risks of symptomatic vaginal candidiasis after oral antibiotic therapy. Q J Med 1993;86:419-24.

55. Loke YK, Price D, Herxheimer A; Cochrane Adverse Effects Methods Group. Systematic reviews of adverse effects: frame- work for a structured approach. BMC Med Res Methodol 2007;7:32

56. Ioannidis JP, Evans SJ, Gotzsche PC, et al. Better reporting of harms in randomized trials: an extension of the CONSORT statement. Ann Intern Med 2004;141:781-8.

57. Pitrou I, Boutron I, Ahmad N, et al. Reporting of safety results in published reports of randomized controlled trials. Arch Intern Med 2009;169:1756-61.

58. Hodkinson A, Kirkham JJ, Tudur-Smith C, et al. Reporting of harms data in RCTs: a systematic review of empirical assessments against the CONSORT harms extension. BMJ Open 2013; 3:e003436.

59. Zorzela L, Golder S, Liu Y, et al. Quality of reporting in systematic reviews of adverse events: systematic review. BMJ 2014;348:f7668.

Affiliations: NPS MedicineWise Ltd. (Gillies), Sydney, New South Wales, Australia; Center for Clinical Epidemiology and Evidence-Based Medicine (Ranakusuma), Faculty of Medicine, University of Indonesia - Cipto Mangunkusumo Hospital, Jakarta, Indonesia; Centre for Research in Evidence-Based Practice (Hoffmann, Thorning, Glasziou, Del Mar) and Faculty of Health Sciences and Medicine (McGuire), Bond University, Gold Coast, Queensland, Australia.

Contributors: Malcolm Gillies, Paul Glasziou and Christopher Del Mar undertook the study concept. All authors contributed to its design, the search strategy and the analysis. All authors contributed to writing and reviewing the manuscript, all approved the version submitted for publication, and all agreed to act as guarantors for the work.

Funding: This study was conducted as a project of the Centre for Research Excellence in Minimising Antibiotic Resistance in Acute Respiratory Infections, with funding for the centre provided by the National Health and Medical Research Council (NHMRC) of Australia (grant 1044904). Paul Glasziou is supported by NHMRC Australia Fellowship 527500. Tammy Hoffmann is supported by NHMRC/Primary Health Care Research, Evaluation and Development Career Development Fellowship 1033038. NPS MedicineWise provides salary support for Malcolm Gillies.

Data sharing: The dataset is available on request from the corresponding author at cdelmar@bond.edu.au

Acknowledgements: The authors would like to thank Elaine Beller (associate professor of biostatistics at the Centre for Research in Evidence-Based Practice, Bond University, Gold Coast, Australia) for statistical advice and Jeffrey Aronson (reader in clinical pharmacology at Oxford University, Oxford, UK) for feedback and advice on previous versions. 